2012

\title{
The Elevation to Area Relationship of Lake Behnke
}

Kaitlin Deutsch

University of South Florida

Advisors:

Arcadii Grinshpan, Mathematics and Statistics

Laurie Walker, Director of USF Botanical Gardens

Problem Suggested By: Van Deryl Wagner

Field of Study for Problem Suggester: Facilities Planning and Construction, USF

Follow this and additional works at: https://digitalcommons.usf.edu/ujmm

Part of the Mathematics Commons

UJMM is an open access journal, free to authors and readers, and relies on your support:

Donate Now

\section{Recommended Citation}

Deutsch, Kaitlin (2012) "The Elevation to Area Relationship of Lake Behnke," Undergraduate Journal of Mathematical Modeling: One + Two: Vol. 4: Iss. 2, Article 5.

DOI: http://dx.doi.org/10.5038/2326-3652.4.2.5

Available at: https://digitalcommons.usf.edu/ujmm/vol4/iss $2 / 5$ 


\title{
The Elevation to Area Relationship of Lake Behnke
}

\begin{abstract}
The objective of this project was to determine the area-to-depth relationship in Lake Behnke, which acts as the principal stormwater drainage basin for the University of South Florida campus in Tampa, Florida. Data previously collected in a stormwater management study by Jeffery Earhart illustrated a linear correlation between the lake's area and depth; however, that study was conducted in 1998, and this present work serves to double check that correlation. We analyzed a bathymetric map of Lake Behnke that displayed several contour lines indicating depth and approximated the area inside each closed curve with a contour integral. The resulting relationship between area and elevation was determined to be more parabolic than linear.
\end{abstract}

\section{Keywords}

Stormwater management, Depth, Bathymetry

\section{Creative Commons License}

(c) (i) (8)

This work is licensed under a Creative Commons Attribution-Noncommercial-Share Alike 4.0 License. 


\section{TABLE OF CONTENTS}

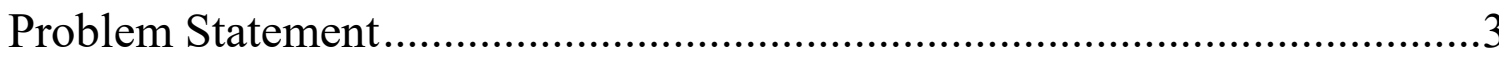

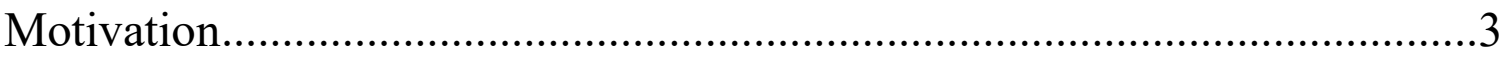

Mathematical Description and Solution Approach ........................................5

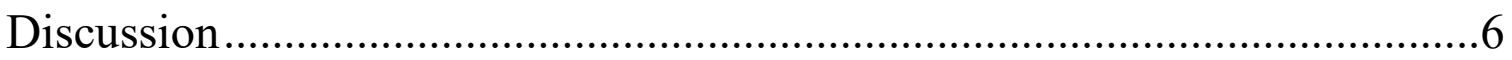

Conclusion and Recommendations ........................................................12

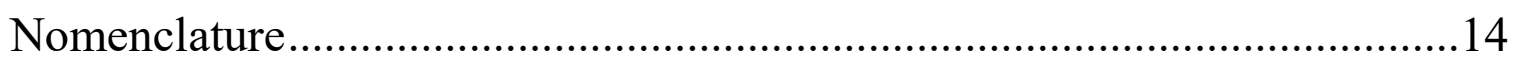

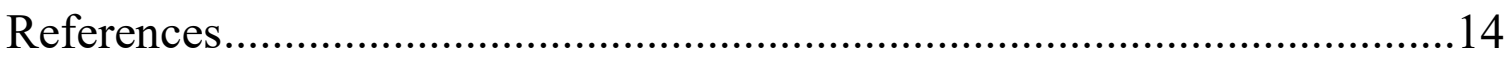

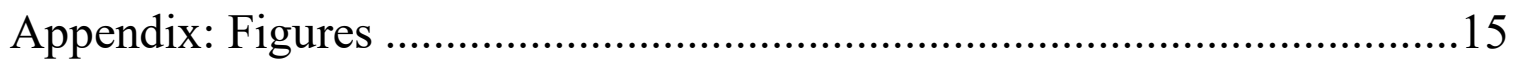




\section{PROBLEM STATEMENT}

Given the bathymetric map of Lake Behnke, determine the areas that correspond to each elevation and evaluate how this relationship compares to the results of previous studies conducted on the lake.

\section{MOTIVATION}

Lake Behnke is a natural sinkhole feature and a "pseudo retention pond" located in the USF Botanical Gardens, serving a particularly important purpose as the main drainage basin for the majority of the run-off from the west side of campus (Foley). Stormwater must be retained in Lake Behnke in order to meet the county's “pre-development vs. post-development volume requirement" (Earhart); that is, no more additional run-off is allowed to leave campus property than before the university was built. Because the buildings and paved areas take up a lot of space, less water is absorbed into the ground, resulting in an increase of run-off: not off the campus property, but into Lake Behnke. From an environmental standpoint, retaining this excess water is important as run-off often contains various pollutants that can be harmful to the environment. Holding them on the campus property in a retention basin prevents those pollutants from damaging natural ecosystems beyond USF, such as the Hillsborough River, which hosts a great diversity of organisms in addition to providing drinking water for the city of Tampa (Foley).

A 1998 Future Condition Analysis for stormwater management provided a stage-storage relationship for the lake, illustrating how the volume changes with respect to elevation (Earhart). Also provided were the areas corresponding to each elevation (see the first two columns of Table 
1), and, when plotted, the elevation-to-area relationship turned out to be almost perfectly linear (see Fig. 2), with a correlation coefficient of 0.9992 , indicating an extremely strong relationship.

\begin{tabular}{|c|c|c|}
\hline Elevation (ft) & Area (acres) & Cumulative Volume (acre-feet) \\
\hline 29.5 & 18.67 & 0 \\
\hline 29.6 & 18.82 & 1.87 \\
\hline 29.7 & 18.97 & 3.76 \\
\hline 29.8 & 19.12 & 5.67 \\
\hline 29.9 & 19.28 & 7.59 \\
\hline 30 & 19.43 & 9.52 \\
\hline 30.1 & 19.57 & 11.47 \\
\hline 30.2 & 19.7 & 13.44 \\
\hline 30.3 & 19.84 & 15.41 \\
\hline 30.4 & 19.97 & 17.4 \\
\hline 30.5 & 20.11 & 19.41 \\
\hline 30.6 & 20.24 & 21.42 \\
\hline 30.7 & 20.38 & 23.46 \\
\hline 30.8 & 20.51 & 25.5 \\
\hline 30.9 & 20.65 & 27.56 \\
\hline
\end{tabular}

Table 1: Stage-Storage Relationship of Lake Behnke (Earhart).

The visual representation of this relationship between elevation and area, called a hypsographic curve, is plotted for many lakes (Florida Lakewatch). They are extremely useful in predicting the surface area of a lake when the water level rises or drops. Since Lake Behnke is a retention basin for excess run-off, it is important to know how much water it can hold and how much the surface area can expand before USF exceeds its post-development run-off output. In extreme weather conditions, this becomes absolutely critical. For example, the maximum surface area for Lake Behnke during the peak of a 25-year, 24-hour storm event (a significantly large storm that has a $4 \%$ chance of occurring any given year (Foley)) is approximately 33.091 acres (Earhart); anything over this would exceed the designated output for the campus and possibly 
cause flooding. Therefore, having an accurate and up-to-date hypsographic curve is very important. From an environmental standpoint, an accurate hypsographic curve can also predict the best time to implement lake management policies, such as habitat restoration and vegetation management. These strategies are most effective when the water is at a particular level.

Because knowing the precise relationship between depth and area is so important and because the data from the 1998 Stormwater Management Study was more than ten years old, we conducted this project to update the analysis and to evaluate whether the relationship displayed in the 1998 data was still accurate today.

\section{MATHEMATICAL DESCRIPTION AND SOLUTION APPROACH}

In order to find the area at varying elevations in the lake, a bathymetric map, illustrating the underwater topography, was used (see Figure 3) (Florida Center for Community Design and Research, Hillsborough County, and Southwest Florida Water Management District). This map was made in 2011 and is therefore reflective of Lake Behnke's current condition. Of the five contour lines, each with a 2 foot difference in elevation, only the first four were analyzed, as the fifth ( 8 feet below surface level) was restricted to very small pockets in the lake at its few deepest points. Thus, this project focused on the area within the contour lines of 0 feet, 2 feet, 4 feet, and 6 feet below the surface level, with the surface level at approximately 29.64 feet above sea level.

The method used to estimate the surface area utilized the contour integral. The concept is similar to that of the Riemann Sums: a simple closed curve is partitioned into a number $n$ of subintervals, with a single arbitrary point near the center. Each partition has an angle $\Delta \theta_{k}$, with the summation of all angles equal to $2 \pi$. A particular length, from the center point to the side of 
the curve, corresponds to an angle at the center and is denoted $\rho(\theta)_{k}$; that is, the length as a function of the angle. The contour integral $\frac{1}{2} \int_{c} \rho(\theta)^{2} d \theta$ gives the area within a closed curve, and this integral can be approximated by the sum $\frac{1}{2} \sum_{k=1}^{n} \rho(\theta)_{\mathrm{k}}^{2} \Delta \theta_{k}$ when $\mathrm{n}$ (the number of partitions) approaches infinity and the maximum $\Delta \theta_{k}$ value (where $1 \leq k \leq n$ ) approaches zero. The greater the number of partitions, the more accurate the approximation of the area will be.

The contour lines on the bathymetric map were traced, producing a mirror image of each closed curve, which was then partitioned into many subintervals (see Fig. 4-7). All angles were measured with a protractor; for large sections of the map, either $\frac{2 \pi}{15}$ or $\frac{\pi}{5}$ were used as each $\Delta \theta_{k}$ value, and for the smaller sections, a $\Delta \theta_{k}$ value of $\frac{2 \pi}{5}$ or $\frac{\pi}{6}$ was used. Each $\rho(\theta)_{k}$ value was measured in centimeters (resolution to $0.05 \mathrm{~cm}$ ) from the center point to a side on the closed curve, and then converted to feet using the scale provided with the bathymetric map. The summation of the $\rho(\theta)_{k}^{2} \Delta \theta_{k}$ values for each elevation (the approximate area) was then converted from square feet to acres in order to compare with the data from the Stormwater Management Study.

\section{DISCUSSION}

From the approximations, the resulting areas were determined to be 18.98 acres at the surface, 16.81 acres at 2ft-depth, 12.96 acres at 4ft-depth, and 7.03 acres at $6 \mathrm{ft}$-depth (see Table 2). A scatter plot of these estimates gave a hypsographic curve that was more parabolic than linear (see Fig. 8). The best-fit line for the data points was determined to be

$$
y=0.0296 x^{2}-0.2783 x+24.157
$$


with a correlation coefficient of 0.9967 . The small coefficient in front of the x-squared term indicates an extremely shallow curve that is almost linear, but not quite. Although the elevation to area relationship was different from that of the 1998 study, the fact that decreasing elevation correlates with decreasing area remained the same.

\begin{tabular}{|c|c|c|}
\hline Feet Below Surface Level & Elevation (ft) & Surface Area (acres) \\
\hline 6 & 23.64 & 7.0333 \\
\hline 4 & 25.64 & 12.9578 \\
\hline 2 & 27.64 & 16.8092 \\
\hline
\end{tabular}

Table 2: Lake Behnke Area vs. Elevation (approximations).

Not only was the relationship between elevation and area found to be different from the earlier result, but the areas themselves were quite different as well. In the 1998 study, the area at the bottom of the lake was 18.67 acres at an elevation of 29.5 feet. The newly obtained data gave the area as 7.0333 acres for the bottom of the lake, at an elevation of 23.64 feet. Somehow, Lake Behnke's depth had substantially increased and the area of the lake-floor significantly decreased. What could have caused such an extreme change in the 14 years between the two studies?

One explanation that can account for this is the previously mentioned fact that Lake Behnke is a natural sinkhole feature: it has a layer of soluble bedrock that is easily dissolved by chemical processes (also referred to as karst processes), making the layers of earth atop slowly cave in as well (University of Texas at Austin). As a retention basin, Lake Behnke also receives a large volume of water, and the additional pressure of this water combined with the natural karst processes probably caused an even more pronounced sinking effect. During the fourteen years between the Stormwater Management study and the current project, it is probable that a lot more of the underlying rock was dissolved and Lake Behnke sunk lower, changing water depths and 
areas at any given elevation. As the lake sunk further and further down, the areas near the bottom became smaller and smaller.

Because the areas at all elevations were so drastically decreased, we explored additional explanations. Since Florida has been currently experiencing a drought, the surface area may have shrunk due to evaporation. Since Lake Behnke collects stormwater, a lack of precipitation means a lack of water, and therefore the decrease in area may be partially due to a lower water level.

Another possible explanation for the significantly reduced areas is sedimentation. Since Lake Behnke collects stormwater run-off, it also traps sediment contained in that water (Clemson University). Sediment "filling in" the sides and the bottom of the lake could account for the drastic reduction in areas. However, this seems to be incongruous with the fact that the lake bottom decreased in elevation, as we would expect the lake to have a higher elevation if it is being filled by sediment.

Sedimentation may explain some of the decrease in areas, but looking further into the technical presentation of the data leads one to examine the possible sources of error: the 6 foot discrepancy in elevations between the two studies may be more than the changes in geology, weather, or sedimentation can fully account for. One technical reason for this discrepancy may be from different vertical data used as reference points for the elevation measurements (where a vertical datum is defined as "a coordinate surface to which heights, taken as vertical coordinates of points, are referred" (Vanicek)). Essentially, each vertical datum is a specific zero level point used as the reference point to give the elevation of other points on the earth's surface (Parker, Milbert and Hess). The elevation measurements used to create the bathymetric map in 2011 (Figure 3) referenced the National Geodetic Vertical Datum of 1929 (NGVD29) (Florida Center for Community Design and Research, Hillsborough County, and Southwest Florida Water 
Management District), while the vertical datum used in the earlier 1998 study is not known.

Given the 6 foot difference in elevation, it is quite possible that the use of different vertical data contributed to the discrepancy.

Another technical error that could account for such a large difference in elevation and area is the interpretation of the bottom of the lake. Looking at the stage-storage relationship illustrated in Table 1, we determined the bottom of Lake Behnke to be at an elevation of 29.5 feet, where the cumulative volume of the lake was 0 acres-feet. However, some stormwater management studies use the cumulative volume of 0 acres-feet not for the lake bottom, but for the bottom of the outgoing pipes somewhere near the surface. The studies do not account for the volume below this, as the only volume of water that will outflow from the lake is the few feet of water above these pipes. If this were the case in the 1998 Stormwater Management Study for Lake Behnke analyzed here, then the elevation at the surface would be somewhere between 29.5 - 30.9 feet (depending on the water level), with a surface area between 18.67 and 20.65 acres. This would be in accord with this project, which has Lake Behnke at an elevation of 29.64 feet and a surface area of 18.97 acres, suggesting that the physical environment has not experienced as extreme of a change in any of the ways described above. However, the linear relationship between elevation and area from the Stormwater Mangagement Study (Figure 1) would still 


\section{Elevation vs. Surface Area (Stormwater Management Study)}

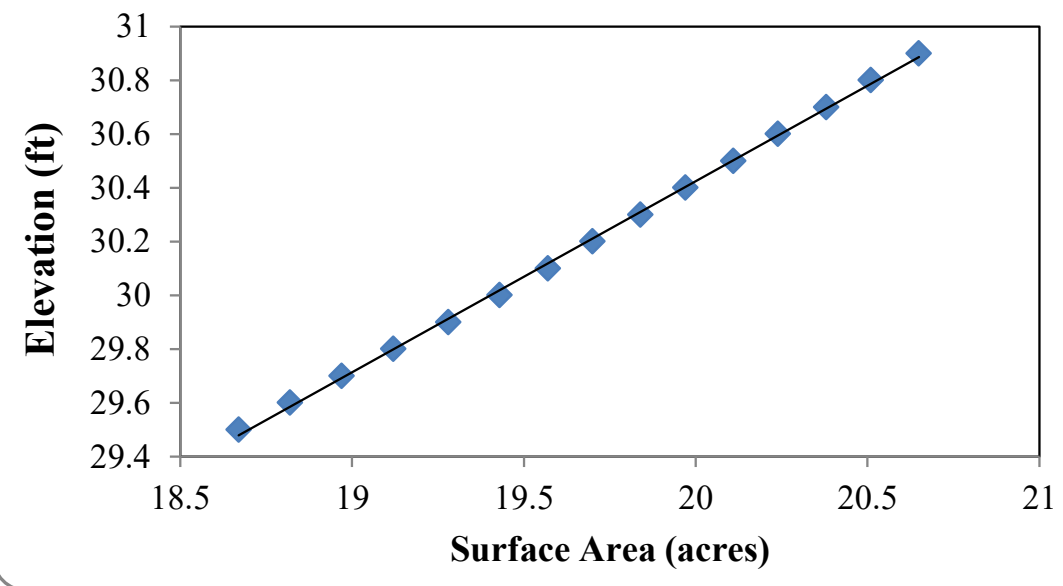

Elevation v. Area

_ Linear (Elevation v. Area)

$y=0.7106 x+16.212$ $\mathrm{R}^{2}=0.9992$

Figure 1: Stormwater Management Study (1998).

differ from the parabolic relationship obtained using the approximations in this project (Figure 8). But in this way, the difference in elevation, as well as in the area-to elevation relationship, can be explained with a combination of the environmental changes and technical differences between the 1998 study and the current project.

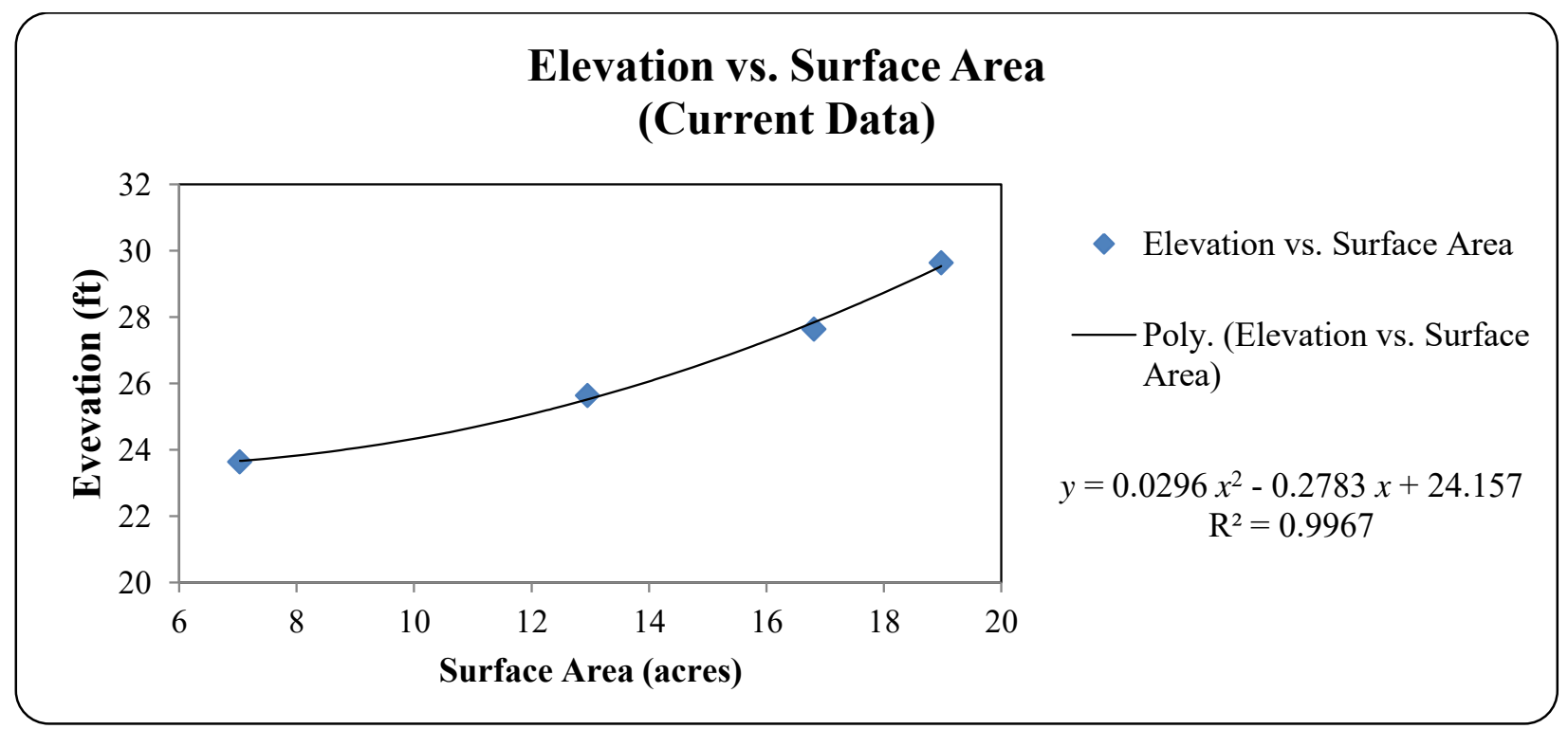

Figure 2: Elevation vs. Surface Area plot of current project data. 
It was previously stated how important it is that an accurate relationship between area and depth be established. As shown above, however, the topography of the lake has likely changed extensively during the 14 years between the two studies, due to karst processes, sedimentation, and weather conditions. As a direct result of this project, an up-to-date stage-storage relationship (with the bottom of the lake clearly defined) could be determined for Lake Behnke. This would prevent run-off outflow from exceeding the designated requirements and provide an accurate hypsographic curve to help predict the rise and fall of water levels.

This project also illuminates the need to evaluate sources of sediment loading from USF campus and the eventual need for dredging. If there is too much sediment "filling in" the lake, it will not be able to retain as much water, and can possibly lead to flooding or the campus exceeding its outflow requirement. If too much sedimentation has occurred, it would be necessary to find the sources from which the sediment is coming from, or at least to remove the excess sediment from the bottom of Lake Behnke.

On a larger scale, this project has implications that can benefit the entire field of lake morphology. It illustrates the importance of knowing the physical and environmental aspects of a lake: because Lake Behnke is a karst feature, its topographical maps, the stormwater management plan, and the corresponding stage-storage relationships will need to be re-assessed more often than for a lake that is not sinking. After fourteen years, the original data from the Stormwater Management study were quite different than the data obtained from approximating the areas of bathymetric map, indicating that measurements for Lake Behnke should be updated much more often. 


\section{CONCLUSION AND RECOMMENDATIONS}

From the project, it can be concluded that the relationship between elevation and area in the 1998 Stormwater Management study is most likely out of date and no longer accurately describes the bathymetry of the lake. Recognizing that the two studies may have referenced different vertical data when determining elevations is important in explaining the discrepancy between the projects, as is the interpretation of the bottom of the lake and the elevation measurement when the cumulative volume is 0 acres-feet. However, there are many other factors that may have resulted in a physical change of the elevation to area relationship. Because the geology of the land surrounding Lake Behnke is known, it was hypothesized that the data became so out-dated due to the dissolution of the carbonate bedrock layer below the lake, causing it to sink further down. Additionally, Florida has been experiencing a drought recently, which could have caused the surface area to shrink as the volume of water entering the lake decreased. A complement to this hypothesis is that sediment from the run-off has filled in the bottom of the lake and decreased the areas at each elevation.

Since Lake Behnke is the main drainage basin for half of the USF campus, it is very important to know its physical capacity to hold water and the maximum surface area it can contain without exceeding the post-development outflow regulations. It is also important in that a great concentration of pollutants may end up in the lake, and having a different depth-to-area relationship may change the lake's capacity to dilute these pollutants (Florida Lakewatch). Also of importance is the flow of polluted stormwater into the aquifer, if Lake Behnke is a sinkhole in direct connection to the water table.

If this project is to be repeated, accuracy could be increased by partitioning the closed curves of the contour map into even more subintervals. More partitions and the subsequent 
smaller angles will give a better approximation of the area given by the contour integrals and thus a better approximation of the area within the contour lines of the map. Additionally, a bathymetric map with more precise measurements of area according to depth would also increase the accuracy of the results. A map that measured the depth and area every foot instead of every two feet would give a better hypsographic curve, as the curve in Figure 8 only had 4 points.

To make the data comparable, a future study should transform the measurements taken from the 1998 study (if they did not use NGVD29) into measurements that reference the National Geodetic Vertical Datum of 1929, the vertical datum used to create the 2011 bathymetric map. Also, a clear definition of where the elevation measurements begin (i.e. the bottom of the lake or the bottom of the outgoing pipes) would likewise help determine how much of a difference is really due to geological changes, weather conditions, and sedimentation rather than simply inconsistencies in measurements.

This project also suggests that other relationships beyond elevation and area may have changed within Lake Behnke, and further projects would be to investigate what other parameters have changed. For example, in regards to the stage-storage relationship provided in the Stormwater Management study, the relationship between depth and volume may be very different now as compared to 1998 if the differences between the studies were primarily due to environmental change. In the event of a major storm, it is important to know how much water Lake Behnke can hold, and this relationship, among others can be established by a re-evaluation of the lake. 


\section{NOMENCLATURE}

\begin{tabular}{|c|l|c|}
\hline Symbol & \multicolumn{1}{|c}{ Description } & Unit \\
\hline$\Delta \theta_{k}$ & Angle Measurement & Degrees \\
\hline$\rho\left(\theta_{k}\right)$ & Length from the Center Point to a Side & $\rho\left(\theta_{k}\right)$ \\
\hline$k$ & Any Subinterval in the Partition of a Closed Curve & \\
\hline
\end{tabular}

\section{REFERENCES}

Clemson University. "Stormwater Pond Design, Construction, and Sedimentation." 2012. Clemson University Cooperative Extension. April 2012

$<$ http://www.clemson.edu/extension/natural_resources/water/stormwater_ponds/construct_repair _dredge/index.html>.

Earhart, Jeffrey J. Final Future Condition Analysis: University of South Florida Master Stormwater Management Study. Orlando: Dyer, Riddle, Mills, and Precourt (Engineers, Surveyors, Planners), 1998.

Florida Center for Community Design and Research, Hillsborough County, and Southwest Florida Water Management District. "Lake Behnke." 18 November 2011. Hillsborough County \& City of Tampa Water Atlas. April 2012

$<$ http://www.hillsborough.wateratlas.usf.edu/upload/bathymetry/Behnke11red.pdf $>$.

Florida Lakewatch. A Beginner's Guide to Water Management - Lake Morphometry. Gainesville: Department of Fisheries and Aquatic Sciences, Institute of Food and Agricultural Sciences, University of Florida, 2001.

Foley, D. Introduction to Environmental Science Laboratory Manual. Tampa: University of South Florida, 1993.

Parker, Bruce, et al. "National VDatum - The Implementation of a National Vertical Datum Transformation Database." U.S. Hydrographic Conference 2003 Proceedings/Technical Papers. 2003. 1-9.

University of Texas at Austin. "What is Karst?" 15 November 2011. Environmental Science Institute, University of Texas. April $2012<\mathrm{http}: / /$ www.esi.utexas.edu/outreach/caves/karst.php>.

Vanicek, Petr. "Vertical Datum and NAVD 88." Surveying and Land Information Systems, Vol. 51, No. 2 (1991): 83-86. 


\section{APPENDIX: FIGURES}

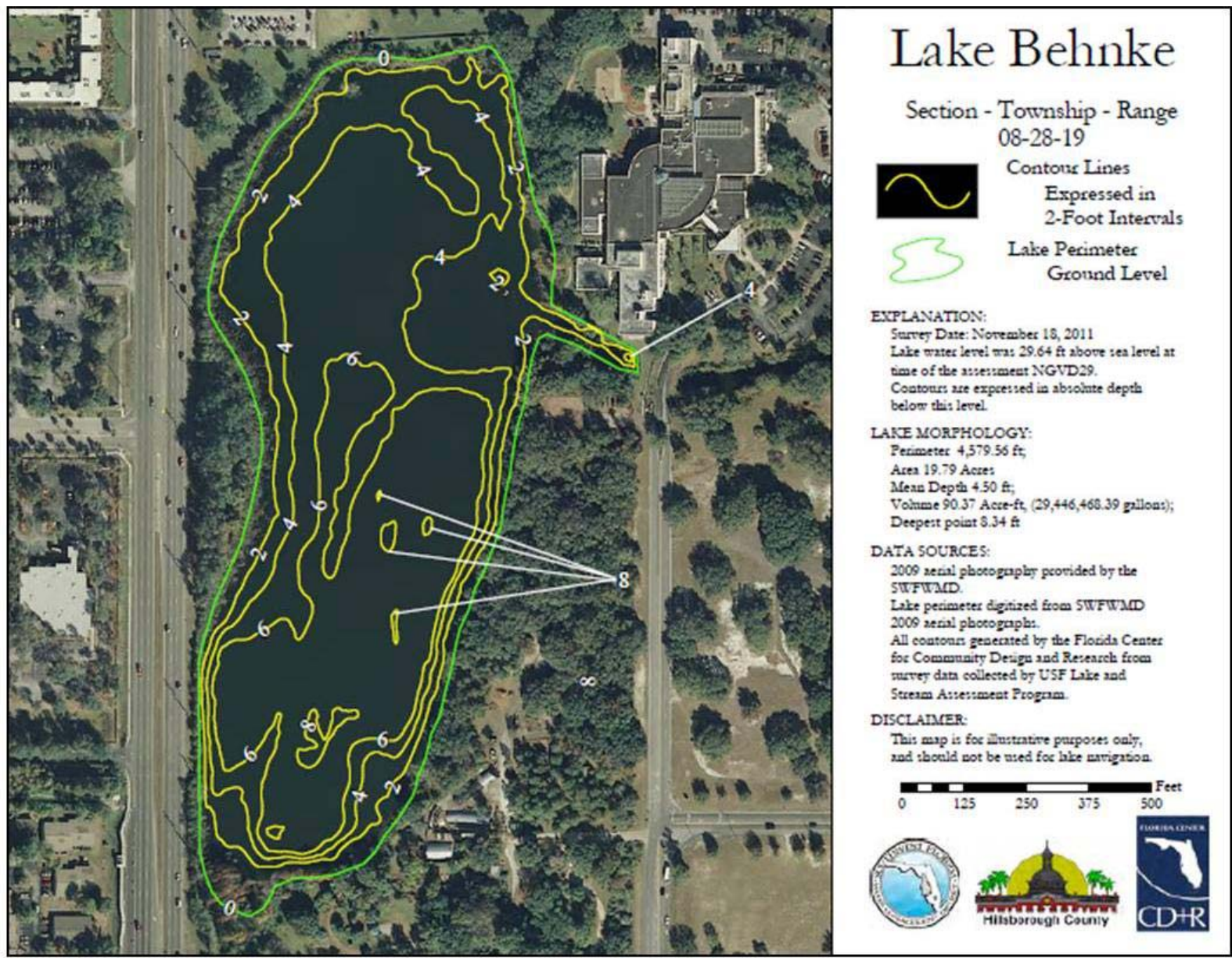

Figure 3: Bathymetric Map of Lake Behnke. 


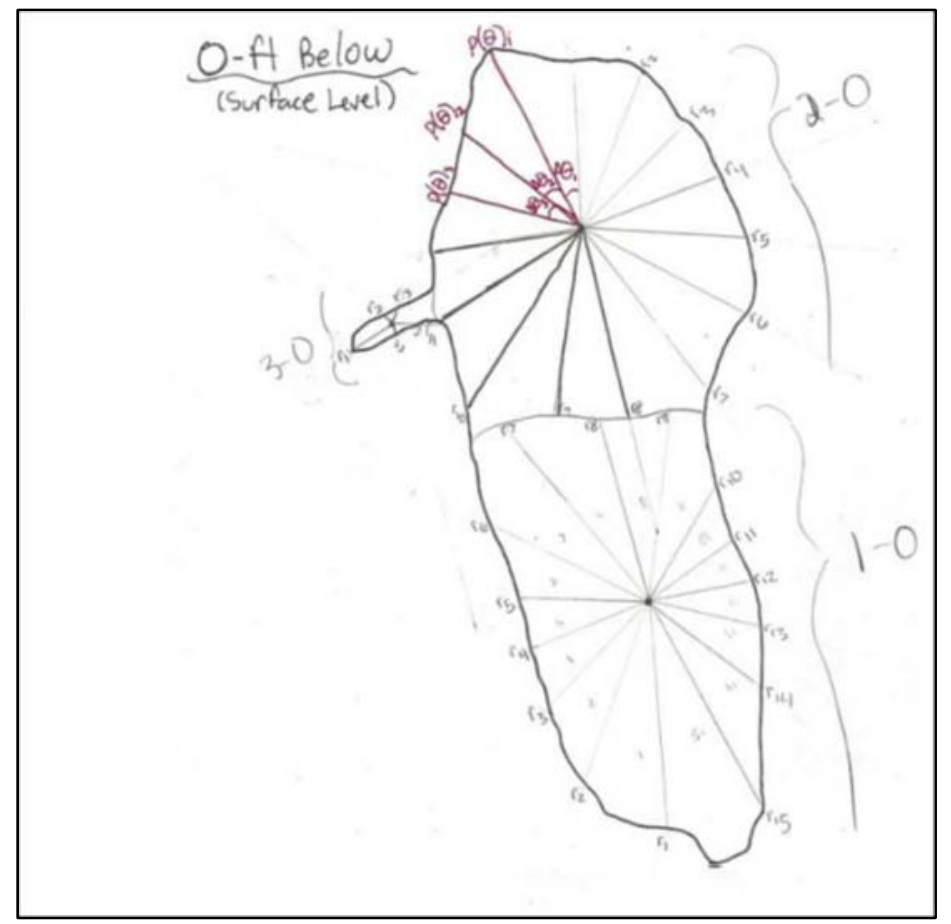

Figure 4: Approximation of the area $0 \mathrm{ft}$ below surface level.

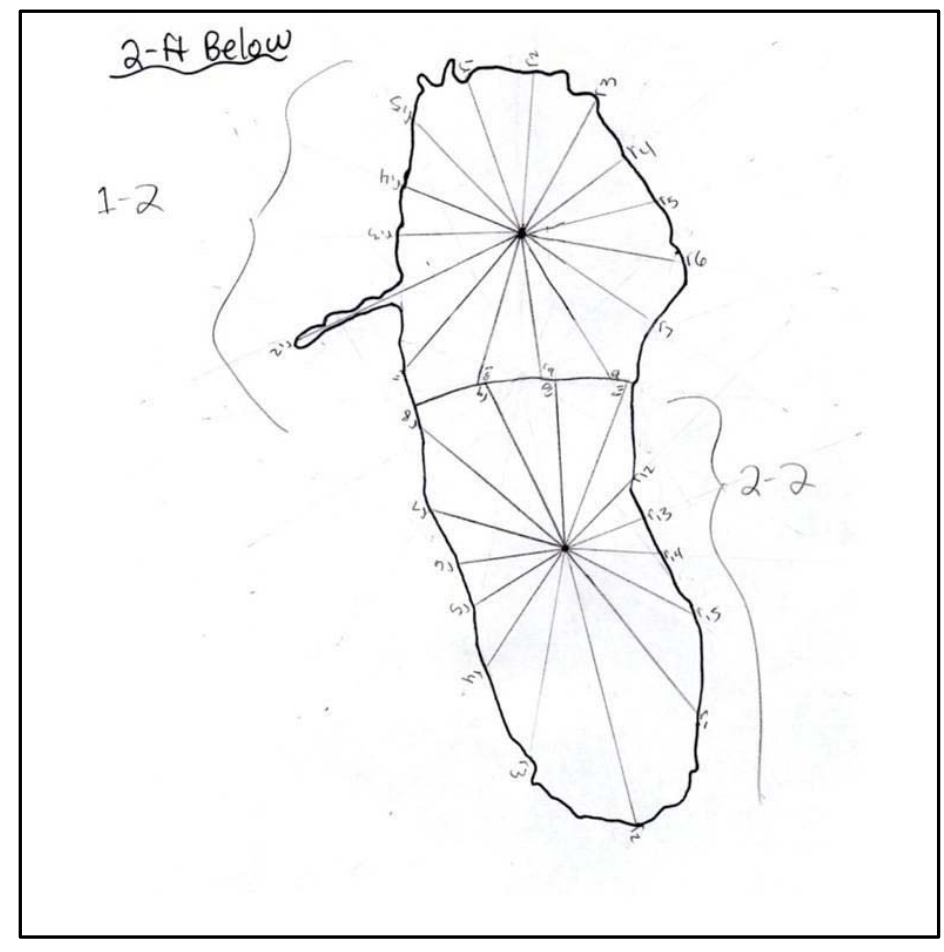

Figure 5: Approximation of the area $2 \mathrm{ft}$ below surface level. 


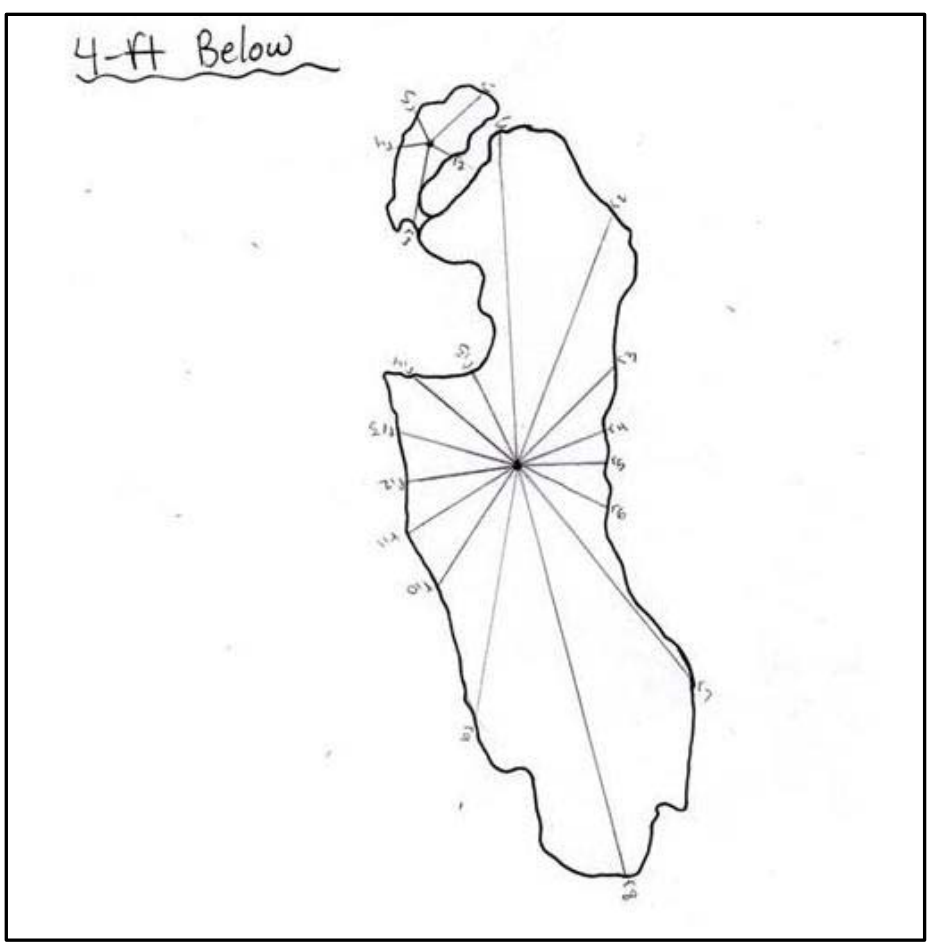

Figure 6: Approximation of the area $4 \mathrm{ft}$ below surface level.

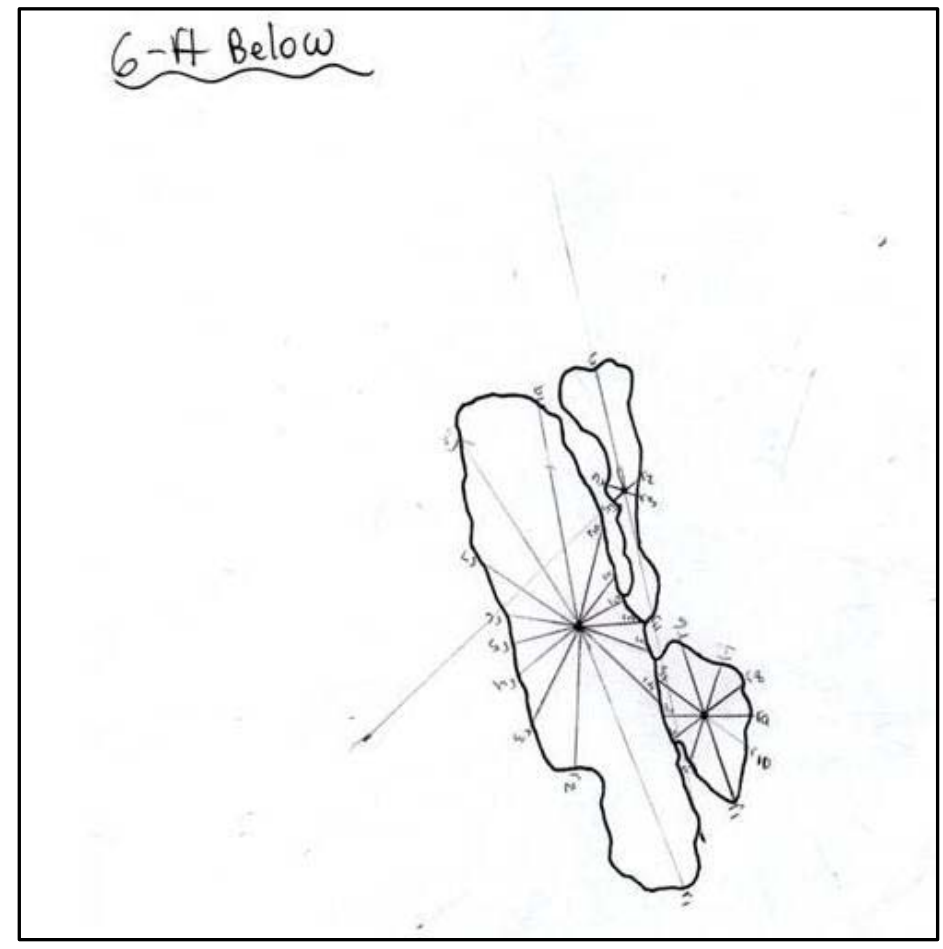

Figure 7: Approximation of the area $6 \mathrm{ft}$ below surface level. 